\title{
Penentuan Urutan Prioritas Pemeliharaan Bangunan SMA Bina Generasi Bangsa Meulaboh-Aceh Barat
}

\author{
Edi Mawardi* ${ }^{1}$, Rahmat Djamaluddin ${ }^{2}$ \\ ${ }^{1,2}$ Jurusan Teknik Sipil, Fakultas Teknik, Universitas Teuku Umar, Alue Penyareng Meulaboh 23615 \\ e-mail: *1eddy_melbon@yahoo.com,2rahmatdj.78@gmail.com
}

\begin{abstract}
ABSTRAK
Bangunan sekolah sebagai sarana pendidikan untuk kelancaran proses belajar mengajar. Dengan pemeliharaan gedung yang kurang baik menyebabkan berbagai fungsi fasilitas gedung semakin menurun dan mempengaruhi kualitas dan kenyamanan pengguna gedung. Apabila kerusakan komponen gedung dibiarkan maka secara perlahan umur layan gedung akan berkurang. Melihat fungsi dari bangunan Sekolah Menengah Atas (SMA) Bina Generasi Bangsa Meulaboh, maka sudah seharusnya bangunan ini mendapat pemeliharaan yang baik agar keandalan dan kelayakan bangunan secara arsitektur, struktur, maupun utilitas tetap terjaga dan berfungsi secara optimal. Tujuan penelitian ini untuk mengetahui prioritas pemeliharaan gedung. Metode analisis yang digunakan metode statistik dan Analytical Hierarcy Process $(A H P)$. Hasil analisis urutan prioritas pemeliharaan elemen asitektur dapat prioritas pertama yaitu penutup atap, sedangkan prioritas kedua pada elemen struktural yaitu kolom, balok dan plat lantai. Sedangkan elemen utilitas mendapat prioritas kedua belas dan seterusnya.
\end{abstract}

Kata kunci : Bangunan Sekolah, Urutan Pemeliharaan, Analytical Hierarcy Process (AHP).

\begin{abstract}
Building school as a means of education for the smooth process of teaching and learning. With the maintenance of poor buildings cause the various functions of building facilities decreases and affects the quality and comfort of building users. If the damage to building components is left then slowly the service life of the building will decrease. View function of High School building Bina Generasi Bangsa Meulaboh, then it should be this building gets good maintenance for the reliability and feasibility of buildings in the architecture, structure, and utilities remain awake and function optimally. The purpose of this research is to know the priority of building maintenance. The method of analysis used statistical methods and Analytical Hierarcy Process (AHP). The result of analysis of priority sequence of maintenance of asitektur element can be first priority that is roof covering, while second priority on structural element that is column, beam and floor plate. While the utility element gets the twelfth priority and so on.
\end{abstract}

Keywords : School Building, Order of Maintenance, Analytical Hierarcy Process (AHP).

\section{PENDAHULUAN}

$\mathrm{P}$ emeliharaan gedung secara konsisten sudah menjadi persyaratan yang harus dipenuhi, utamanya bagi bangunan yang difungsikan untuk kepentingan umum. Gedung sekolah merupakan salah satu fasilitas umum yang perlu dipelihara dan layak pakai demi kepentingan proses belajar mengajar. Sekolah Menengah Atas (SMA) Bina Generasi Bangsa Meulaboh Kabupaten Aceh Barat, bangunan tersebut dibangun Adventist Development and Relief Agency (ADRA) tahun 2007 dan berada di Kecamatan Johan Pahlawan Kabupaten Aceh Barat. 
Bangunan direncanakan dapat beroperasi selama masa layan tertentu. Namun, selama masa layan tersebut bangunan dapat mengalami perubahan kualitas atau penurunan kekuatan yang disebabkan berbagai macam faktor seperti faktor usia bangunan, faktor alam, faktor manusia akibat penggunaan gedung, beban yang berlebih, kebakaran atau sebab lainnya.

Sesuai dengan pendoman pemeliharaan dan perawatan bangunan gedung Peraturan Menteri Pekerjaan Umum Nomor 24/PRT/M/2008, menyatakan perawatan bangunan gedung adalah kegiatan memperbaiki dan/atau mengganti bagian bangunan gedung, komponen, bahan bangunan dan/atau prasarana dan sarana agar bangunan gedung tetap laik fungsi. SMA Bina Generasi Bangsa Meulaboh sudah seharusnya bangunan ini mendapat perbaikan agar keandalan dan kelayakan bangunan secara arsitektur, struktur, maupun utilitas tetap terjaga dan berfungsi secara optimal. Namun, berdasarkan survey awal mengindikasikan bahwa kondisi bangunan sekolah ini kurang terawat sehingga perlu dilakukannya penelitian agar dapat ditelusuri permasalahan dan kendala yang terjadi. Dengan dilakukannya penelitian ini diharapkan dapat menghasilkan sebuah konsep operasional pemeliharaan dan perbaikan gedung yang optimal sehingga dapat berfungsi dengan baik.

\section{METODE PENELITIAN}

Pengumpulan data penelitian dilakukan dengan menggunakan metode survey dan analisis data sekunder. Observasi diperoleh dari pengamatan langsung terhadap kondisi gedung. Observasi dilakukan terhadap tiga komponen gedung yaitu struktur, arsitektur dan utilitas. Untuk komponen struktur dilakukan pengecekan kerusakan gedung secara visual terhadap tiga elemen yaitu kolom, balok dan plat lantai. Untuk komponen arsitektur dilakukan pengecekan kerusakan secara visual terhadap beberapa elemen yaitu dinding, lantai, langit-langit, kusen, pintu dan jendela. Untuk komponen utilitas dilakukan pemerikasaan visual terhadap instalasi listrik dan air serta alat-alat sanitasi apakah masih berfungsi secara baik. Hasil dari observasi diperoleh tingkat kerusakan masing-masing komponen. Dari nilai tersebut dapat dikategorikan persentase kerusakan bangunan dalam tiga kategori yaitu rusak ringan, rusak sedang, atau rusak berat. Selain observasi secara visual, dilakukan mengukur volume yang harus dilakukan perbaikan. Berikut ini gambar situasi kerusakan bangunan SMA Bina Generasi Bangsa Meulaboh. 
Vol. 4 No.1 April 2018

pp. $12-20$

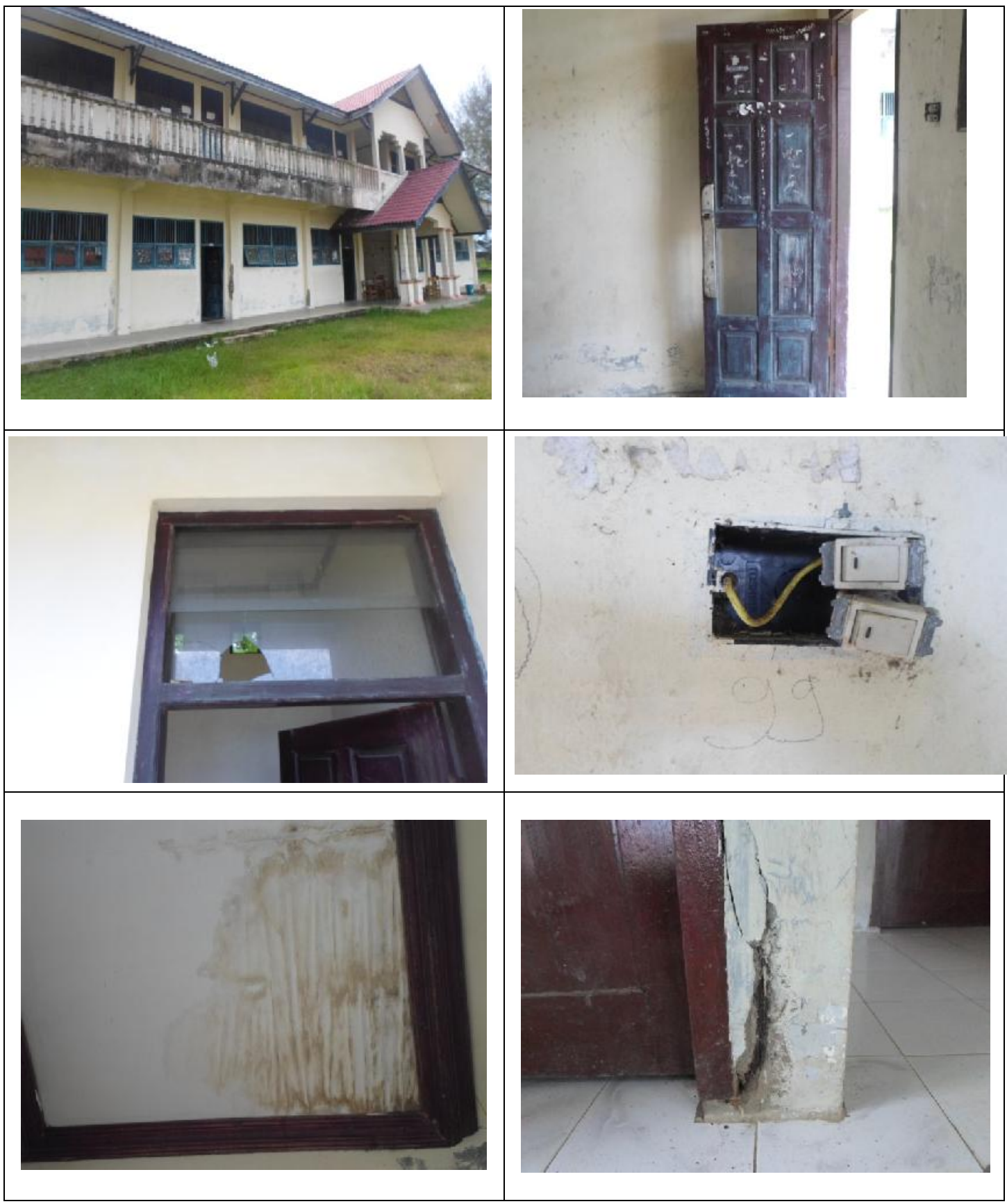

Gambar 1 Situasi Kerusakan pada SMA Bina Generasi Bangsa Meulaboh

Wawancara, dilakukan terhadap key informant yang menjadi pengelola atau penanggung jawab pada gedung sekolah tersebut bertujuan menggali informasi mengenai perbaikan/perawatan gedung agar dapat urutan prioritas pemeliharaan. Untuk pengumpulan data sekunder diperoleh data perencanaan awal gedung untuk mengetahui spefikasi gedung, serta data struktur organisasi pengelolaan gedung sekolah tersebut.berikut ini gambar lampiran wawancara terhadap key informant. 


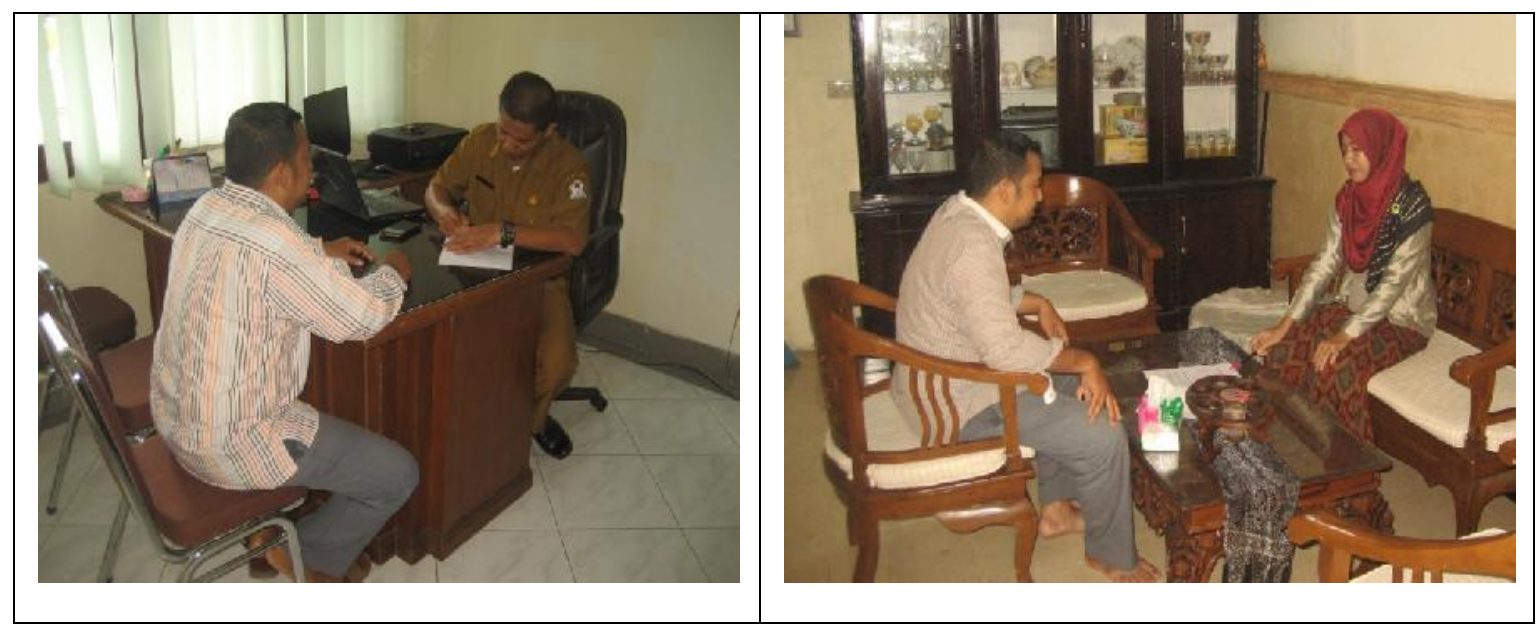

Gambar 2 Proses wawancara dengan Penanggung Jawab Gedung

AHP adalah prosedur yang berbasis matematis yang sangat baik dan sesuai untuk kondisi Atribut-atribut tersebut secara matematik dikuantitatif dalam 1 set perbandingan berpasangan. Kelebihan AHP dibandingkan yang lainnya karena adanya struktur yang berhirarki, sebagai konsekuensi dari kriteria yang dipilih, sampai kepada sub-sub criteria yang paling mendetail. Memperhitungkan validitas sampai dengan batas toleransi inkonsistensi berbagai kriteria dan alternatif yang dipilih oleh para pengambil keputusan (Saaty, 1990). Karena menggunakan input persepsi manusia, model ini dapat mengolah data yang bersifat kualitatif maupun kuantitatif. Jadi kompleksitas permasalahan yang ada di sekitar kita dapat didekati dengan baik oleh model AHP ini. Selain itu AHP mempunyai kemampuan untuk memecahkan masalah yang multi-objektif dan multi-kriteria yang didasarkan pada perbandingan preferensi dari setiap elemen dalam hierarki. Jadi model ini merupakan suatu model pengambilan keputusan yang komprehensif. Kemampuan metode AHP yang digunakan di sini adalah dalam analisis konsistensi dan analisis sensitivitas. Analisis konsistensi ditujukan tehadap hirarki prioritas yang dibangun. Sedangkan analisis sensitivitas dimaksudkan untuk melihat pengaruh setiap elemen terhadap hirarki prioritas yang dibangun.

Ada beberapa langkah yang dibutuhkan untuk menentukan prioritas pemeliharaan gedung dengan metoda AHP ini, yaitu:

\section{Menentukan nilai prioritas pemeliharaan.}

Untuk lebih mudah menganalisis setiap pemeliharaan disingkat/lambing dengan PML, PML 1 (Program 1) lebih penting dari pada PML 2 (Program 2), pemeliharaan 2 kurang penting dibanding dengan PML 3 (Program 3), dsb, namun mengalami kesulitan menyebutkan seberapa penting PML 1 dibandingkan PML 2 atau seberapa kurang pentingnya PML 2 dibandingkan dengan PML 3. Untuk itu kita perlu membuat tabel konversi dari pernyatan prioritas ke dalam angka-angka, skala nilai prioritas pemeliharaan seperti pada Tabel 1. 
Tabel 1 Skala pemeliharaan dan definisinya

\begin{tabular}{|c|l|}
\hline Nilai & \multicolumn{1}{|c|}{ Definisi } \\
\hline 1 & PML 1 A sama penting di bandingkan PML 1 B \\
\hline 3 & PML 1 A sedikit lebih penting dengan PML 2 B \\
\hline 5 & PML 1 A lebih penting di bandingkan dengan PML 2 B \\
\hline 7 & PML 1 A sangat penting di bandingkan dengan PML 2 B \\
\hline 9 & PML 1 A jauh sangat penting di bandingkan dengan PML 2 B \\
\hline $2,4,6,8$ & Nilai tengah-tengah/diantara \\
\hline
\end{tabular}

\section{Melakukan Perbandingan Setiap PML}

Selanjutnya adalah membuat tabel perbandingan prioritas setiap PML dengan membandingkan masing-masing PML. Proses menbandingkan antar PML diperoleh nilai prioritas PML, seperti pada Tabel 3 Cara mengisinya adalah dengan menganalisa prioritas antara PML baris dibandingkan dengan PML kolom. Dalam prakteknya kita hanya perlu menganalisa prioritas PML yang terdapat dibawah pada garis diagonal yang ditunjukan dengan warna kuning atau diatas garis diagonal yang ditunjukan dengan kotak warna hijau. Hal ini sesuai dengan persamaan matematika yang menyebutkan jika $\mathrm{A}: \mathrm{B}=\mathrm{X}$, maka $\mathrm{B}: \mathrm{A}=1 / \mathrm{X}$. Contoh: jika prioritas PML A (baris) : PML $\mathrm{B}$ $($ kolom $)=5$, maka prioritas PML A (baris) $:$ PML B (kolom) $=1 / 5$ (lihat rumus persamaan perbandingan matematika).

\section{Penentuan Bobot PML}

Selanjutnya adalah menentukan bobot pada tiap PML, nilai bobot ini berkisar antara 0 - 1 . Dan total bobot untuk setiap kolom adalah 1. Cara menghitung bobot adalah angka pada setiap kotak dibagi dengan penjumlahan semua angka dalam kolom yang sama. Penentuan bobot dapat dilihat pada Tabel 3 (Tabel Perbandingan Prioritas Setiap Program Pemeliharaan) dan Tabel 3 (Tabel Penentuan Bobot Setiap Program Pemeliharaan)

Selanjutnya adalah menentukan bobot pada tiap PML, nilai bobot ini berkisar antara 0 - 1 . Dan total bobot untuk setiap kolom adalah 1. Cara menghitung bobot adalah angka pada setiap kotak dibagi dengan penjumlahan semua angka dalam kolom yang sama (Merujut pada lampiran B.3.1). Contoh bobot dari (PML-1 A, PML-1 A) $=1 /(1+0,33+1+0,33+1+0,33+0,2+0,2+0,14+$ $0,14+5+0,2+0,2+0,2+0,2+0,2+0,2+0,2+0,14+0,33+0,33+0,14+0,14+0,14+0,2+$ $0,2+0,2)=0.0774,($ PML $2 \mathrm{~A}, \mathrm{PML} 1 \mathrm{~B})=0,33 /(1+0,33+1+0,33+1+0,33+0,2+$ $0,2+0,14+0,14+5+0,2+0,2+0,2+0,2+0,2+0,2+0,2+0,14+0,33+0,33+0,14+0,14+$ $0,14+0,2+0,2+0,2)=0.0285$. Dengan perhitungan yang sama bobot maka prioritas PML dapat diperoleh. 
Vol. 4 No.1 April 2018

pp. 12 - 20

Tabel 2 Perbandingan Prioritas Setiap Program Pemeliharaan

\begin{tabular}{|c|c|c|c|c|c|c|c|c|c|c|c|c|c|c|c|c|c|c|c|c|c|c|c|c|c|c|c|}
\hline & $\begin{array}{l}\text { 를 } \\
\stackrel{2}{\leftrightarrows} \\
\text { 흠 } \\
\check{4}\end{array}$ & 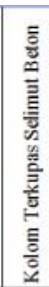 & 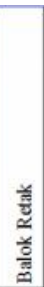 & 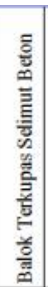 & 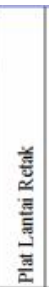 & 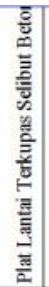 & 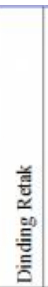 & 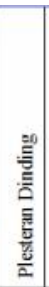 & 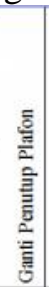 & 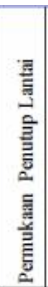 & 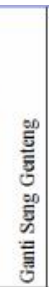 & 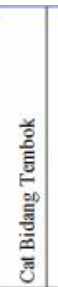 & 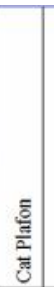 & 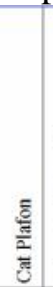 & 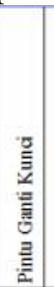 & 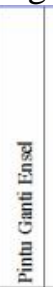 & 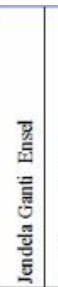 & 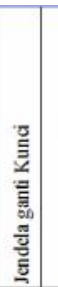 & 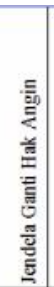 & 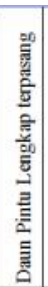 & 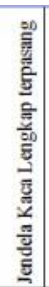 & 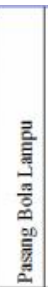 & 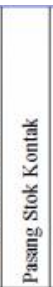 & 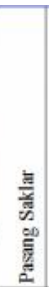 & 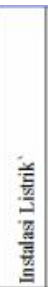 & 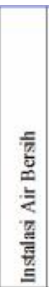 & 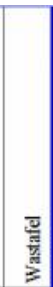 \\
\hline Kolom & & 3,00 & 1,00 & 3,00 & 1,00 & 3,00 & 5,00 & 5,00 & 7,00 & 7,00 & 0.20 & 5,00 & 5,00 & 5,00 & 5,00 & 5,00 & 5,00 & 5,00 & 7,00 & 3,00 & 3,00 & 7,00 & 7,00 & 7,00 & 5,00 & 5,00 & \\
\hline $\begin{array}{c}\text { Kolom Terkupas } \\
\text { Selimut Beton }\end{array}$ & 0.33 & 1,00 & 0.33 & 1.00 & 0.33 & 1.00 & 3,00 & 3.00 & 5,00 & 5.00 & 0.14 & 3,00 & 3.00 & 5,00 & 5,00 & 5,00 & 5,00 & 5,00 & 7.00 & 3.00 & 3,00 & 5,00 & 5.00 & 5,00 & 5.00 & 5,00 & \\
\hline Balok & & 3,00 & 1,00 & 3,00 & 1,00 & 3,00 & 5,00 & 5,00 & 7,00 & 7,00 & 0.20 & 5,00 & 5,00 & .00 & 5,00 & 5,00 & 5,00 & 5,00 & 7,00 & 3,00 & 3,00 & 3,00 & 5,00 & 5,00 & 5,00 & 5,00 & \\
\hline $\begin{array}{l}\text { Balok Terkupas } \\
\text { Selimut Beton }\end{array}$ & 33 & 1,00 & 0,33 & 1,00 & 0,33 & 1,00 & 3,00 & 5,00 & 5,00 & 5,00 & 0,33 & 3,00 & 3,00 & 5,00 & 5,00 & 5,00 & 5,00 & 3,00 & 7,00 & 3,00 & 3,00 & 5,00 & 5,00 & 5,00 & 5,00 & 5,00 & \\
\hline Plat Lantai Retak & & 3,00 & 0,33 & 3,00 & 1,00 & 1,00 & 5,00 & 7,00 & 3,00 & 5,00 & 0,33 & 3,00 & 3,00 & 3,00 & 5,00 & 5,00 & 5,00 & 5,00 & 7,00 & 3,00 & 3,00 & 3,00 & 5,00 & 3,00 & 3,00 & 3,00 & \\
\hline $\begin{array}{c}\text { Plat Lantai } \\
\text { Terkupas Selibut }\end{array}$ & & 1,00 & 0,33 & 1,00 & 1,00 & 1,00 & 3,00 & 3,00 & 5,00 & 3,00 & 0,14 & 3,00 & 3,00 & 3,00 & 5,00 & 5,00 & 5,00 & 5,00 & 7,00 & 3,00 & 3,00 & 7,00 & 7,00 & 7,00 & 5,00 & 5,00 & \\
\hline Dinding Retak & & 0. & 0 & 0,33 & 0,20 & 0,33 & 1.00 & 3,00 & 1,00 & 1,00 & 0,14 & 2,00 & 3,00 & 3,00 & 3,00 & 3,00 & 3,00 & 3,00 & 5,00 & 0,50 & 0,50 & 1,00 & 1,00 & 1,00 & 1,00 & 1,00 & \\
\hline & & 0.33 & 0.20 & 0,33 & 0,14 & 0,33 & 0.33 & 1,00 & 1,00 & 1,00 & 0,14 & 5,00 & 3.00 & 3,00 & 3.00 & 3.00 & 3,00 & 3.00 & 1,00 & 5,00 & 5,00 & 3,00 & 3,00 & 3.00 & 1.00 & 1,00 & \\
\hline $\begin{array}{r}\text { Ganti Pe } \\
\text { Plafo }\end{array}$ & 14 & 0,20 & 0,14 & 0,20 & 0,33 & 0,20 & 1.00 & 1,00 & 1,00 & 1,00 & 0,11 & 5,00 & 3,00 & 7,00 & 3,00 & 3,00 & 3,00 & 3,00 & 5,00 & 1,00 & 1,00 & 3,00 & 3,00 & 3,00 & 1,00 & 1,00 & 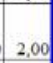 \\
\hline $\begin{array}{l}\text { Permul } \\
\text { Penutup }\end{array}$ & & 0,20 & 0,14 & 0,20 & 0,20 & 0,33 & & & & 1,00 & 0.14 & 5,00 & 5,00 & 7,00 & 3,00 & 3,00 & & 3,00 & 5,00 & 1,00 & 1,00 & 3,00 & 3,00 & 3,00 & 1,00 & 1,00 & 1,0 \\
\hline & & 7,00 & 00 & 3,00 & & & & & & & 1,0 & & & & & 3,00 & & & 3,00 & 5,00 & 5,00 & 3,00 & 3,00 & 5,00 & 1,00 & 1,00 & \\
\hline $\begin{aligned} \text { Cat F } \\
\text { Ten }\end{aligned}$ & & 0,33 & 0,20 & 0,33 & 0,33 & & 0,50 & 0,20 & 0,20 & & & 1,0 & 1,00 & & & 0,50 & 1,00 & 1,00 & 3,00 & 1,00 & 1,00 & 3,00 & 3,00 & 3,00 & 3,00 & 3,00 & \\
\hline & & 0.33 & 0.20 & 0,33 & 0,33 & 0,33 & 0,33 & 0,33 & 0,20 & 0,20 & 0.33 & 1,00 & 1,00 & 1,00 & 0,50 & 0,50 & 1,00 & 1,00 & 3.00 & 1,00 & 1,00 & 1,00 & 1,00 & 1,00 & 1,00 & 1,00 & \\
\hline & & 0,20 & 0,20 & 0.20 & 0,33 & 0,33 & & 0.33 & 0.14 & 0,14 & 0,33 & 1,00 & 1,00 & 1.00 & 0,50 & 0,50 & 1,00 & 1,00 & 1,00 & 1,00 & 1,00 & 1,00 & 3,00 & 3,00 & 3,00 & 1,00 & \\
\hline $\begin{array}{r}\text { Pintu } \\
\mathrm{Kr} \\
\text { Pintu }\end{array}$ & & 0,20 & 0,20 & 0,20 & 0,20 & 0,33 & 0,33 & 0,33 & 0,33 & 0,33 & 0,20 & 2,00 & 2,00 & 2,00 & 1,00 & 1,00 & 1,00 & 1,00 & 3,00 & 0,33 & 0,33 & 1,00 & 1,00 & 1,00 & 0,20 & 0,20 & \\
\hline & 20 & 0.20 & 0,20 & 0,20 & 0,20 & 0,20 & 0,33 & 0,33 & 0,33 & 0,33 & 0,33 & 2,00 & 2,00 & 2,00 & 1,00 & 1,00 & 1,00 & 1,00 & 1,00 & 0,33 & 0,33 & 1,00 & 1,00 & 1,00 & 0,14 & 0,14 & 0,5 \\
\hline $\begin{array}{l}\text { Jendela Ganti } \\
\text { Ensel }\end{array}$ & & 0.20 & 0,20 & 0,20 & 0.20 & & & & & 0,33 & 0,33 & 1,00 & 1,00 & 1,00 & 1,00 & 1,00 & 1,00 & 1,00 & 1,00 & 0.20 & 0.20 & 1,00 & 1,00 & 1,00 & 0.50 & 0.50 & \\
\hline $\begin{array}{c}\text { Jendela ganti } \\
\text { Kunci }\end{array}$ & & 0.20 & 0,20 & & & & & & & 0,33 & & 1,00 & 1,00 & & 1,00 & 1,00 & 1,00 & 1.00 & 3,00 & 0,33 & 0,33 & 1,00 & 1,00 & 00 & 0,50 & 0,50 & \\
\hline $\begin{array}{c}\text { Jendela Gant } \\
\text { Hak Angin }\end{array}$ & & 0,14 & 0,14 & 0,14 & & & & 1,00 & 0.20 & & & & & & & 1,00 & 1,00 & 0.33 & 1,00 & 0,33 & 33 & 25 & .25 & 0,50 & 0,50 & 0,50 & 0.2 \\
\hline & & 0,33 & 0,33 & 0,33 & 0,33 & & 2,00 & 0,20 & 1,00 & 1,00 & 0,20 & 1,00 & 1,00 & 1,00 & 3,00 & 3,00 & 5,00 & 3,00 & 3,00 & 1,00 & 1,00 & 1,00 & $0,50 \mid$ & 0,50 & 1,00 & 1,00 & 1,0 \\
\hline $\begin{array}{c}\text { Jendela Kaca } \\
\text { Lengkap }\end{array}$ & & 0. & 0,33 & 33 & & 0,33 & 2,00 & 0,20 & 1,00 & 1,00 & 0,20 & 1,00 & 1,00 & 1,00 & 3,00 & 3,00 & 5,00 & 3,00 & 3,00 & 1,00 & 00 & 1,00 & \begin{tabular}{|l|l|} 
\\
\end{tabular} & 0,50 & 1,00 & 00 & \\
\hline $\begin{array}{c}\text { Pasang Bola } \\
\text { Lampu }\end{array}$ & & 0,20 & 0.33 & 20 & 0,33 & 0,14 & 1,00 & 0,33 & 0,33 & 0,33 & 0,33 & 0,33 & 1,00 & 1,00 & 1,00 & 1,00 & 1,00 & 1,00 & 4,00 & 1,00 & 1.00 & .00 & 1,00 & 1,00 & 1,00 & 1,00 & 0.2 \\
\hline $\begin{array}{c}\text { Pasang Stok } \\
\text { Kontak }\end{array}$ & & 0.20 & 0,20 & 20 & 20 & 0,14 & Do & 0,33 & 0,33 & 0,33 & 33 & 0,33 & 00 & 0,33 & 1,00 & 00 & 1,00 & 1,00 & 4,00 & 2,00 & 2.00 & 1,00 & 00 & 1,00 & 1,00 & 1,00 & 0,5 \\
\hline Pasang & & 0,20 & 0 , & 0,20 & 0,33 & 14 & 1,00 & 0,33 & 0,33 &, 33 & 0,20 & 0,33 & 1 & 0 &, 00 & & 1,00 & 1,00 & 2,00 & 2,00 & 2,00 & 1,00 & \begin{tabular}{|l|}
1,00 \\
\end{tabular} & 1,00 & 1,00 & 1,00 & \\
\hline Instalasi $\mathrm{Li}$ & 0 & 0.20 & 0 & 20 & 0 & 20 & 1,00 & 1,00 & 1,00 & 1,00 & 1,00 & 0,33 & 1,00 & 33 & 5,00 & 7,00 & 2.00 & 2.00 & 2.00 & 1,00 & 1,00 & 1,00 & 1,00 & 1,00 & .00 & 1,00 & \\
\hline $\begin{array}{c}\text { Instalasi Air } \\
\text { Bersih }\end{array}$ & & 0,20 & 0 , & 20 & 0,33 & 20 & 1,00 & 1,00 & 1,00 & 1,00 & 1,00 & 0,33 & 1,00 & 0,33 & 5,00 & 7,00 & 2,00 & 2,00 & 2,00 & 1,00 & 1,00 & 1,00 & 1,00 & 1,00 & 1,00 & 1,00 & 0,3 \\
\hline Wastafel & & 0.20 & & 0,20 & 0. & 0,33 & & & 0 & & 0 & 0,333 & $00 \mid$ & 0,50 & 00 & & .00] & & 00 & 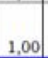 & 00 & 5 & & 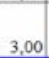 & 00 & 1 & \\
\hline
\end{tabular}

\section{Menentukan Nilai Bobot dan Prioritas}

Selanjutnya adalah mencari nilai bobot untuk masing-masing PML. Dengan melakukan penjumlahan setiap nilai bobot prioritas pada setiap baris tabel dibagi dengan jumlah PML. Sehingga diperoleh bobot masing-masing PML.

Selanjutnya adalah mencari nilai bobot untuk masing-masing PML. Caranya adalah dengan 
melakukan penjumlahan setiap nilai bobot prioritas pada setiap baris tabel dibagi dengan jumlah PML (Merujut pada tabel 3). Sehingga diperoleh bobot masing-masing :

(1) PML I $=(0,0774+0,1264+0,0797+0,1509+0,0780+0,1357+0,1063+0,1043+$ $0,1331+0,1371+0,0222+0,0904+0,0857+0,0783+0,0686+0,0654+0,0685+$ $0,0777+0,0693+0,0666+0,0666+0,1143+0,1057+0,1037+0,0964+0,1003+$ $0,0924) / 27=0,0926(9,26 \%)$.

(2) PML II $=(0,0452+0,638+0,0626+0,0951+0,0979+0,0155+0,0542+0,0514+$ $0,0783+0,686+0,0654+0,0685+0,0777+0,0693+0,0666+0,0666+0,0816+$ $0,0777+0,0693+0,0666+0,0666+0,0816+0,0755+0,0741+0,0964+0,1003+$ $0,0924) / 27=0,0644(6,44 \%)$. dengan perhitungan yang sama dihitung dst..

Tabel 3 Penentuan Nilai Bobot Setiap Program Pemeliharaan

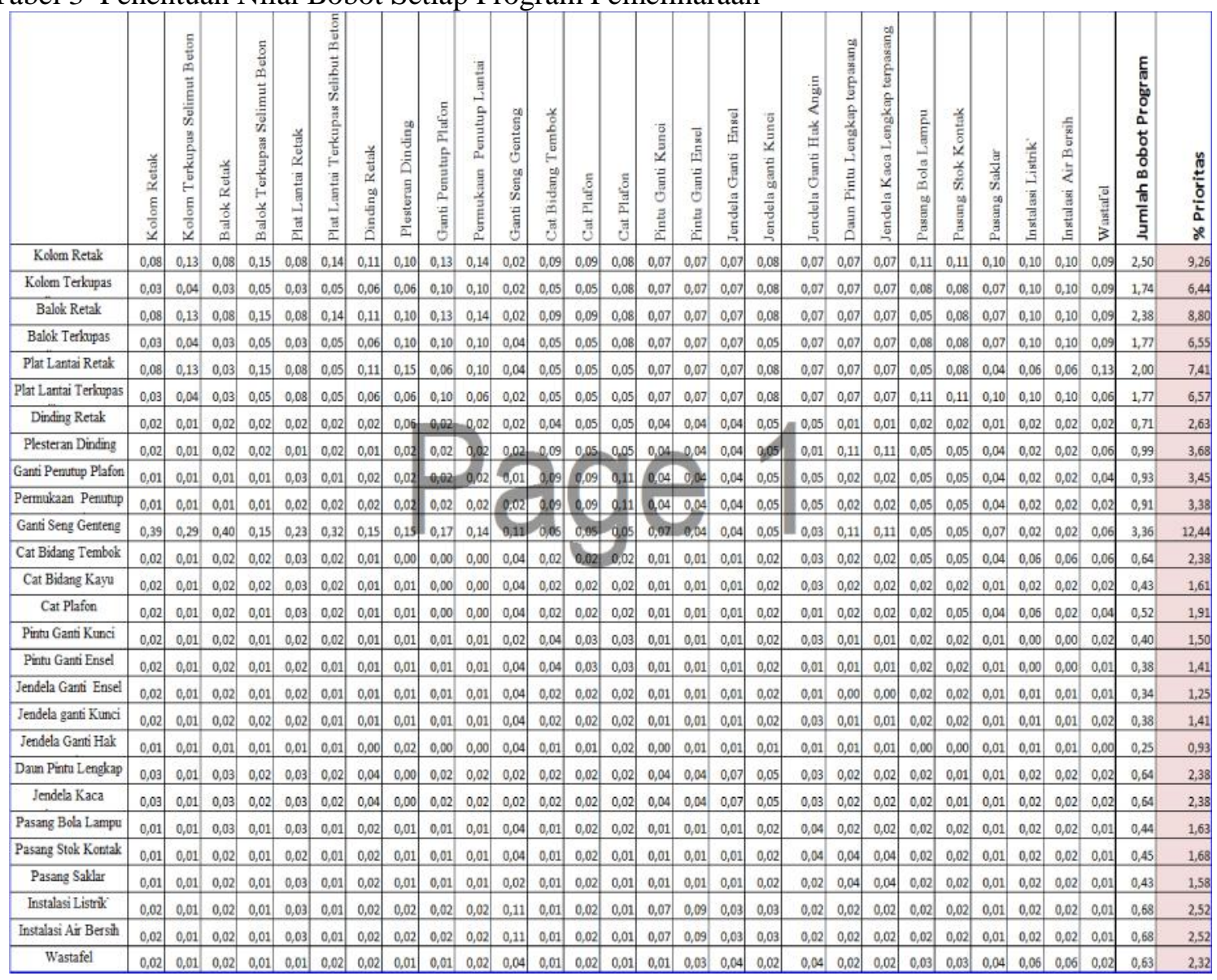

\section{HASIL DAN PEMBAHASAN}

Bangunan sekolah merupakan sebuah bangunan yang berfungsi sebagai tempat kegiatan belajar mengajar bagi siswa. SMA Bina Generasi Bangsa dibangun tahun 2006 setelah dilanda tsunami pada tahun 2004 bangunan tersebut mempunyai 3 (tiga) ruang kelas, lab,ruang dewan guru dan kepala sekolah. Bangunan tersebut dibangun berlantai II. Bangunan tersebut termasuk wilayah bibir pantai jarak dengan laut sekitar 150 meter. Gedung dengan kontruksi beton bertulang yang dibangun dengan perencanaan yang kokoh mampu menahan beban gempa mencapai 9 skala Richter, struktur bangunan beton mutu K-250. 
Vol. 4 No.1 April 2018

pp. $12-20$

\subsection{Penentuan Prioritas Pemeliharaan}

Ada beberapa langkah yang dibutuhkan untuk menentukan prioritas pemeliharaan gedung dengan metode AHP, seperti terlihat pada tabel 4 berikut.

Tabel 4 Nilai Bobot Setiap Pemeliharaan Berdasarkan Skala Prioritas.

\begin{tabular}{|c|c|c|c|c|}
\hline No & Pemeliharaan & $\begin{array}{l}\text { Lambang/ } \\
\text { Singkatan }\end{array}$ & $\begin{array}{c}\% \\
\text { Prioritas }\end{array}$ & $\begin{array}{c}\text { Prioritas } \\
\text { Pemeliharaan }\end{array}$ \\
\hline 1. & Ganti Atap Seng Genteng & PML XI & 12,441 & I \\
\hline 2. & Kolom Retak & PML I & 9,263 & II \\
\hline 3. & Balok Retak & PML III & 8,800 & III \\
\hline 4. & Plat Lantai Retak & PML V & 7,407 & IV \\
\hline 5. & Plat Lantai Terkupas Selibut Beton & PML VI & 6,574 & $\mathbf{V}$ \\
\hline 6. & Balok Terkupas Selimut Beton & PML IV & 6,552 & VI \\
\hline 7. & Kolom Terkupas Selimut Beton & PML II & 6,435 & VII \\
\hline 8. & Dinding Plesteran & PML VIII & 3,679 & VIII \\
\hline 9. & Ganti Penutup Plafon & PML IX & 3,451 & IX \\
\hline 10 & Permukaan Penutup Lantai & PML X & 3,380 & $\mathbf{X}$ \\
\hline 11 & Dinding Retak & PML VII & 2,628 & $\mathbf{X I}$ \\
\hline 12 & Instalasi Listrik' & PML XXV & 2,518 & XII \\
\hline 13 & Instalasi Air Bersih & PML XXVI & 2,517 & XIII \\
\hline 14 & Daun Pintu Lengkap terpasang & PML XX & 2,375 & XIV \\
\hline 15 & Jendela Kaca Lengkap terpasang & PMLXXI & 2,375 & $\mathbf{X V}$ \\
\hline 16 & Cat Bidang Tembok & PML XII & 2,380 & XVI \\
\hline 17 & Wastafel & PML XXVII & 2,318 & XVII \\
\hline 18 & Cat Bidang Plafon & PML XIV & 1,912 & XVIII \\
\hline 19 & Pasang Bola Lampu & PML XXII & 1,679 & XIX \\
\hline 20 & Pasang Stok Kontak & PML XXIII & 1,631 & $\mathbf{X X}$ \\
\hline 21 & Cat Bidang Kayu & PML XIII & 1,607 & XXI \\
\hline 22 & Pasang Saklar & PML XXIV & 1,578 & XII \\
\hline 23 & Pintu Ganti Kunci & PML XV & 1,498 & XXIII \\
\hline 24 & Pintu Ganti Ensel & PML XVI & 1,415 & XXIV \\
\hline 25 & Jendela Ganti Ensel & PML XVII & 1,411 & XXV \\
\hline 26 & Jendela Ganti Kunci & PML XVIII & 1,245 & XXVI \\
\hline 27 & Jendela Ganti Ensel & PML XVII & 0,931 & XXVII \\
\hline \multicolumn{3}{|c|}{ Jumlah } & $100 \%$ & \\
\hline
\end{tabular}

Sehingga jumlah total bobot semua PML $=100 \%$, sesuai dengan kaidah pembobotan dimana jumlah total bobot harus bernilai 100. Tabel 4, menunjukkan bahwa dengan penggunaan metode AHP, maka semua alternative pemecahan masalah (program pemeliharaan) dapat 
ditentukan prioritasnya dengan baik. Dari analisi tersebut diperoleh bahwa Ganti Atap Seng Genteng (12,441\%), menempati prioritas pertama, kemudiaan Kolom Retak $(9,263 \%)$, menempati prioritas kedua, Balok Retak $(8,800 \%)$, merupakan prioritas ketiga dan seterusnya, sedangkan jendela ganti engsel merupakan prioritas terakhir $(0,931 \%)$.

\section{KESIMPULAN}

1. Hasil mengidenfikasi kerusakan pada gedung SMA Bina Generasi Bangsa terdapat komponen yang harus segera dilakukan pemeliharaan agar tidak dampak pada komponen lain. Hal ini disebabkan karena belum adanya kegiatan operasi dan pemeliharaan yang rutin untuk gedung SMA Bina Generasi Bangsa Mdulaboh.

2. Prioritas pertama pemeliharaan adalah pada elemen Asitektur yaitu penutup atap atau ganti atap, sedangkan prioritas berikutnya adalah bidang struktural yaitu kolom, balok yang mengalami keretakan. Serta prioritas berikutnya adalah elemen struktural yang mengalami terkupas selimut beton.

\section{SARAN}

1. Perlu dilakukan perbaikan pada komponen gedung yang mengalami kerusakan agar tidak semakin bertambah parah.

2. Untuk pengelola diharapkan melakukan pemeliharaan bangunan sesuai urutan prioritas sehingga alokasi dana yang dibutuhkan dapat terpenuhi dan staf yang terlibat dalam pemeliharaan dapat menjalankan kewajibannya dengan baik.

\section{DAFTAR PUSTAKA}

[1] Ervianto, W.I., 2007, Studi Pemeliharaan Bangunan Gedung (Studi Kasus Gedung Kampus), Jurnal Teknik Sipil, Vol.7 No.3 Hal 212-223, Universitas Atma Jaya, Yogyakarta.

[2] Kasman Makkasau., 2012, Penggunaan Metode Analytic Hierarchi Process (AHP) Dalam Penentuan Prioritas Program Kesehatan (Studi Kasus Program Promosi Kesehatan),J @TI Udip, Vol. VII No. 2. Hal. 105-112, Universitas Diponegoro, Semarang

[3] Kementrian Pekerjaan Umum, 2007, Peraturan Menteri Pekerjaan Umum Nomor 45/PRT/M/2007 tentang Pedoman Teknis Pembangunan Gedung Negara, Jakarta.

[4] Kementrian Pekerjaan Umum, 2008, Peraturan Menteri Pekerjaan Umum Nomor 24/PRT/M/2008 tentang Pedoman Pemeliharaan dan Perawatan Bangunan Gedung, Jakarta.

[5] Navira, M., 2014, Kajian Sistem Manajemen Operasional Museum Tsunami Aceh, Tesis, Universitas Syiah Kuala, Banda Aceh.

[6] Pemerintah Republik Indonesia, 2002, Undang - Undang Republik Indonesia Nomor 28 Tahun 2002 Tentang Bangunan Gedung, Jakarta.

[7] Rita, 2015, Optimalisasi Sistim Pemeliharaan Gedung Pada Bangunan Penyelamat (Escape Building) di Kota Banda Aceh, Tesis, Universitas Syiah Kuala, Banda Aceh.

[8] Rosalina, 2011, Sistem Pemeliharaan Gedung Ditinjau Dari Keandalan Bangunan Gedung, Studi Kasus Gedung Rumah Susun Sederhana Sewa di Kabupaten Cilacap, Tesis, Universitas Sebelas Maret, Surakarta. 